\title{
System development for the disclosure of Portuguese digital type design
}

\author{
Quelhas, Vítor ${ }^{\mathrm{a}}$; Branco, Vasco ${ }^{\mathrm{b}}$ \& Mendonça, Rui ${ }^{\mathrm{c}}$ \\ ${ }^{a}$ Escola Superior de Música, Artes e Espetáculo do Instituto Politécnico do Porto / ID+, Portugal. \\ vitorquelhas@esmae.ipp.pt \\ bUniversidade de Aveiro / ID+, Portugal.vasco.branco@ua.pt \\ ${ }^{c}$ Faculdade de Belas Artes da Universidade do Porto / ID+, Portugal. ruimendonca@fba.up.pt
}

\begin{abstract}
This study aims to cover the current development of a platform for the disclosure of the Portuguese type design community, since the beginning of the desktop revolution, until today. To deepen our understanding, interviews were made to a selected and representative group of type designers from our sample based on several criteria. The interview tested six dimensions: people, processes, products, uses, identity and platform. The results analysed in the last dimension, through content analysis and quantitative data, lead to the development of an online digital collaborative system - one of our specific objectives. Our hypothesis - that the development of a online digital collaborative system would allow further development of knowledge between products, users and authors, as well as, processes and uses - was also corroborated by the interviewers. Reviews have been made to reference international online projects to identify their purposes, areas of activity, objectives, mechanisms of interaction, usability and accessibility. This previous research brought together a set of notes that would become essential in the definition and development of our concept. The classification of typefaces is a subject of study by researchers and designers, but it is certainly not a topic for complete agreement. Organizing and balancing the content for the database was our first challenge since we were expecting users with good knowledge on the field, but also beginners. Several diagrams were put into test during the early stage of information architecture to better define categories, filters, and sorting methods, as well as users roles in the system. The items and categories chosen were redefined in a second stage, and in the third stage hifidelity wireframes were produced, to concentrate on design aspects and decisions, and put the system into test and evaluation. The current results on the platform development, with the improvements made through several user tests, evaluations and refinements undertaken in all phases of the project have been crucial. We are expecting to run some pilot tests, as well as usability tests prior to the full implementation to further improve the system and meet the expectations.
\end{abstract}

Keywords: Digital type design; Typography; Platform; Process; System 


\section{Introduction}

The study of typefaces is a fairly recent discipline in Portugal. Apart from historical approaches, mainly focusing on printing, since the beginning of the Press until the $17^{\text {th }}$ century, design related research based on the typefaces themselves, their authors and processes are, until today, very scarce.

In recent years, typography has been a topic of growing international interest, with a focus on studying foundries and typefaces that were well-received throughout history.

In the beginning, producing typefaces was a manual, complex and time consuming activity that involved several tools and mechanisms. Nowadays, thanks to the digital revolution, to the easy access to digital tools and to information sharing, all of this process can be done within the scope of a computer. Since the digital revolution, type-making has proliferated and today there is a huge growth in digital foundries, providing quality typefaces (Cahalan, 2007; King, 1999; King, 2001; Kinross, 1992; Leonidas, 2013a; Leonidas, 2013b; Middendorp \& TwoPoints.Net, 2011).

Original type designs in Portugal were, until the digital realm, very little explored, and mainly based on the knowledge of foreign contributions (Anjos, 1886; Anselmo, 1981; Anselmo, 1997; Canhão, 1941; Pacheco, 1998; Pacheco, 2005; Pacheco 2013). In the field of typography and type design, the isolation was only abolished in the early 90s. In the last two decades teaching of typography in schools was promoted, specific subjects were created in universities, and a promising generation of type designers in Portugal started to emerge (Chaccur \& Amado, 2010; Quelhas, Branco \& Heitlinger, 2011).

Typefaces firstly designed by Mário Feliciano and Dino dos Santos, and later on by Ricardo Santos, Rui Abreu, Susana Carvalho, Hugo d'Alte, among others, started to achieve a notable presence in Portugal and abroad, being distributed and recommended in the main digital type foundries around the world. Although their work has been recognized with prestigious awards, honourable mentions, and also with international projects commissions, little is known about their path, processes, products and uses.

This paper addresses the systematic approach underpinned in the design and development of a digital web platform for the disclosure of Portuguese digital type design. This project has been conducted as part of a broader research that aims to analyse, describe and identify the factors that contributed to the continuous growth of the digital type design production and community in Portugal.

The platform aims to tackle the lack of systematization and relevant information about authors, products, uses and distribution, contributing to the awareness and expansion of its national and international visibility. It also intends to contribute to understanding the history of type design in Portugal, providing theoretical and practical knowledge.

\section{Study framework}

A mix of research methods has been used to gather as much information as possible to inform and reveal the necessity of this project. Soon we have realized that studies in our field, Portuguese digital type design, from 1990 until 2010, were scarce or very lightly explored, and the information looked scattered, both in the national and international literature available. Due to the contemporaneity of the research, our main references to similar investigations came, as expected, from the academic community, mainly in the form of master dissertation or thesis (Cahalan, 2007; King, 1999).

Information about Portuguese digital type designers is hard to find. It is also very hard to determine what constitutes nowadays to a renown or professional type designer. If that can be true at an international 
level, in the national scale, the lack of an institutional organization or association that centralizes this data, makes the task of collecting it extremely challenging and it was only possible through the pioneering work of Luc Devroye. In his website ${ }^{71}$ Devroye keeps an online archive with references of type design from all over the world. Although his selection is not classified, this resource lists exhaustively type design creations from Portuguese authors, professionals and amateurs.

Iconographic data on the typefaces were in first place gathered from the type designers personal, professional, or promotional websites, from previous versions of their websites through the Internet Archive, from Devroye list of collected material on Portuguese type design production, from social networks, blogs and forums, from foundries and distributers, as well as from printed sources, mainly catalogues and type specimens.

The form chosen to complement this collection was the use of a survey in the form of interview, as this instrument allows to obtain qualitative data related to values, attitudes, opinions and preferences of the interviewed, as well as the collection of quantitative data whenever deemed necessary (Patton, 2002).

To deepen our understanding on the typefaces, their authors, processes and uses, a series of semistructured interviews were conducted to a selected and representative group of type designers from our universe based on a set of criteria built upon the contributions of related previous researches, mainly King (1999), Cahalan (2007) and Gomes (2010). Each author should at least meet three of the criteria listed below:

- Designers with published typefaces or custom types;

- Designers with typefaces awarded in renowned competitions;

- Designers invited for lectures and conferences;

- Designers cited or distinguished in magazines or related websites;

- Designers recognized by their peers.

Based upon these criteria, ten designers have been selected in order to pursue with the interviews (listed alphabetically): Dino dos Santos; Jorge dos Reis; Hugo d'Alte; Manuel Pereira da Silva, Mário Feliciano; Miguel Sousa; Ricardo Santos; Rui Abreu; Rúben Dias; Susana Carvalho.

The interview was conducted to all these designers, except Manuel Pereira da Silva who unfortunately was no longer with us, tested six dimensions: people, processes, products, uses, identity and platform.

In the first dimension our objective was to better know the author and his work. This part of the questionnaire was focused on training, professional activity in general, the influences and references to national and international levels; the second dimension focused on the process of designing typefaces, trying to understand the relationship between authorship/technology/program (Providência, 2003); the third dimension focused on their perceptions related to the typefaces themselves, the sales rank, awards, and also on perceiving the organization of their typeface production; the forth dimension focused in the uses concerning features such as language expansion for international markets, and understanding theirs opinions on the impact of technologies in their typefaces uses. It was also focused on understanding the gaps in the promotion and uses of national typefaces; the fifth dimension tried to evaluate the perception of each author in relation to the identity of Portuguese typefaces, cultural traits and the differences of their products in the national and international market; and the last dimension was directly related to the need

${ }^{71}$ Luc Devroye Type in Portugal webpage: http://luc.devroye.org/portugal.html 
of creating a platform for the disclosure of Portuguese digital type design, one of our research specific objectives that will be detailed in this paper.

The interview was truly a necessary step to engage with the most relevant authors, understanding their needs and expectations. Involving them in the decision making process was part of our methodology.

\subsection{Organizing and classifying typefaces and related information}

The classification of typefaces is a subject of study by researchers and designers, but it is certainly not a topic of complete agreement. Over time, several methods were designed based on morphologic aspects (BS 2961, 1967; Thibaudeau, 1924; Vox, 1954; Willberg, 2001), historic movements (Bringhurst, 2004 [1992]), mixed classifications (Bauermeister, 1987; Dixon, 2001; Mundie, 1995) and later on with tags (Dixon, 2012). Nowadays, the amount of variables in typeface design and production makes the classification field a very difficult task.

Shaikh (2007) researched also this topic and concluded that "the lack of uniformity among the experts makes it difficult to definitively choose one classification system as the most representative" (p. 11). However, she noted that, the classification system proposed by Spiekermann and Ginger (1993) is comprehensible for beginners: Serif, Sans Serif, Script, Display, and Symbols.

The article 25 Systems for Classifying Typography: A Study in Naming Frequency, by Childers, Griscti and Leben (2013), retrieved the most frequent classification words from a total of 25 classification systems published in the last century, ranging from typographic experts such as Theodore Low De Vinne and Maximilien Vox and ending with contemporary type and design researchers such as Ellen Lupton and Robert Bringhurst, in a new map, divided in three main branches of type design: Serif, Sans Serif, and Topical (for a subdivision of non-text faces) (Fig 1).

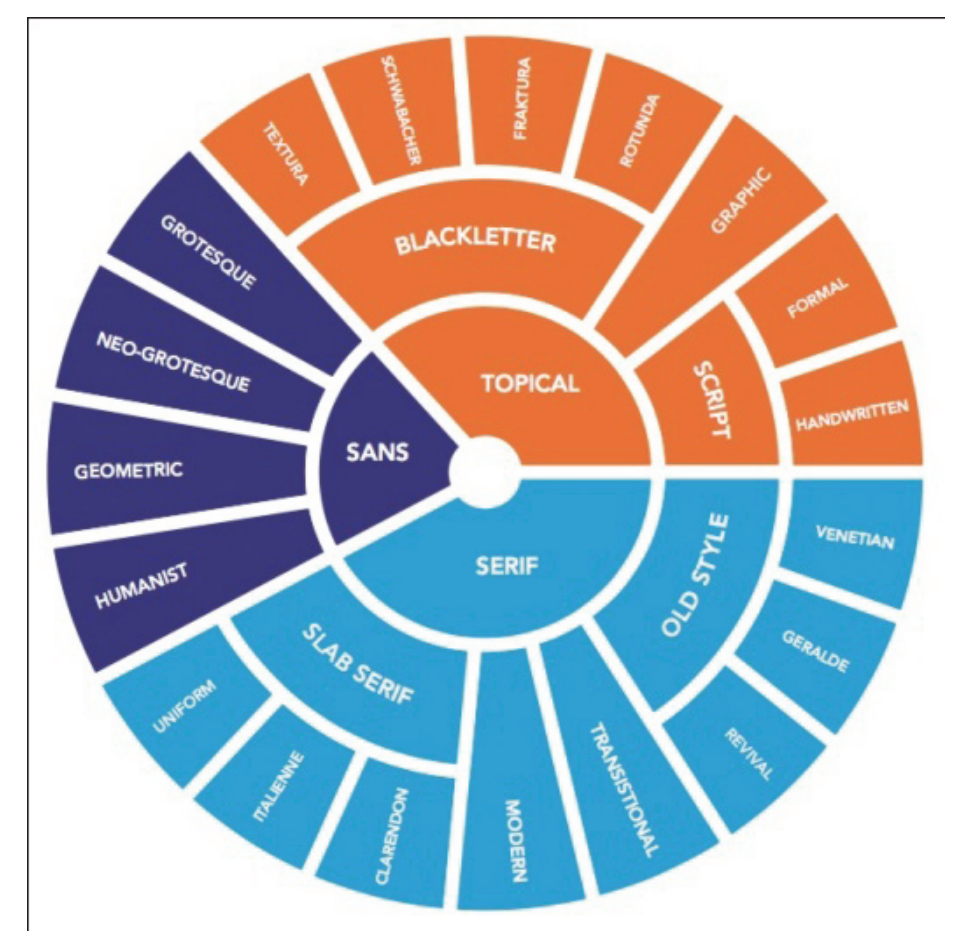

Fig. 1 Taxonomic model for Typeface classification. Source: Childers, Griscti and Leben (2013). 
Childers, Griscti and Leben (2013) refers that, "It is felt that a very high level of specificity is achieved with this model without becoming overtly caught-up up in unnecessary jargon. It is therefore more usual than over-simplified orders and viable for extensive typeface class naming uses." (p. 19).

Merging the frequency of words within the study of Childers, Griscti and Leben (2013), with Shaikh (2007) suggestion of a simplified classification based on Spiekermann and Ginger (1993), with Bringhurst (1992) unique historical approach, and Vox-ATypI morphologic classification, and confronting those findings with the information gathered into similar classification systems in international web platforms, from the most representative type foundries and distributers, a selection of terms were put into test. This helped us to understand the many possible ways to organize, filter and sort typefaces. Organizing and balancing the content for the database was our first challenge since we were expecting users with good knowledge on the field, but also beginners, the amount and ways of sorting and filtering were striped down to the essential jargon. Although we have started with a dozen terms, soon we have realized that it was best to start with a small amount of categories before adding a lot of subclassifications to cover all the typographical details. For the platform we decided to classify typefaces in a cross categorization and flexible system, according to availability (published; custom; unpublished), style (serif; sans serif; handwritten; display; symbols) and function (text; title; web; decorative; non-latin). To facilitate the access, other features and sorting methods were also included (free; families; awarded; order by AZ; most recent). To define the typefaces more specifically other descriptive components were also added to the typefaces in the form of additional searched tags.

\section{The platform}

\subsection{Concept definition, objectives and targeted users}

The results analysed in the last dimension of the questionnaire, both content analysis and quantitative data, was an encouraging footstep that led to the development of an online digital platform.

Our hypothesis - that the development of an online digital collaborative system would allow further development of knowledge among products, users and authors, as well as processes and uses - was also corroborated by the interviewers. This positive feedback encouraged us to continue our research with the development of a project based approach delivered through action-research methodologies.

The main goal of this project is to research and develop a prototype that merges information on digital typefaces, providing room for several ways of organizing them, selecting and deepen our understanding on their authors, their process of development and uses. Currently, the most recent books, blogs, or foundries websites deliver a couple of information regarding a particular typeface, such as the authors name, year, foundry, classification, brief context, purpose of creation or use, among other details. But it is hard to retain and sometimes find those details. 

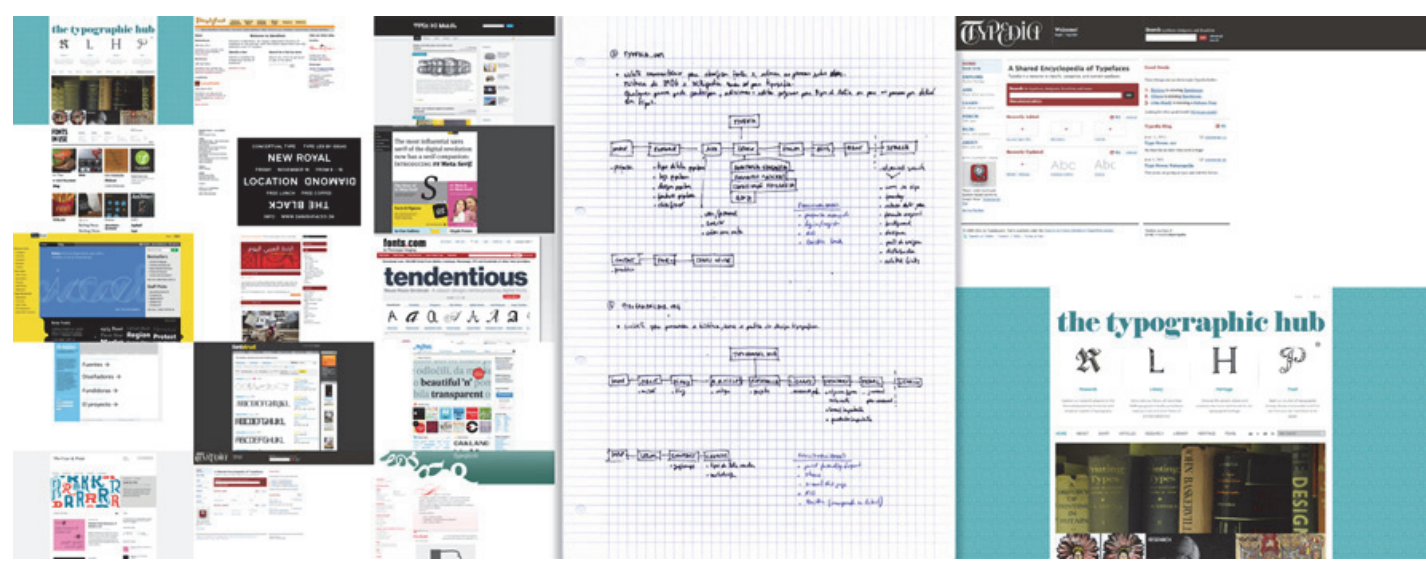

Fig. 2 Previous research and analysis to related international platforms

Studies have been made to similar international online projects to identify their purposes, areas of activity, objectives, mechanism of interaction, usability and accessibility (Fig 2). This previous research brought together a set of notes that became essential in the definition and development of our concept, specially in regard to the classification and sorting of typefaces.

The platform named Portype is developed with two different approaches in mind: first deliver a curated and detailed gallery of typefaces and their authors, from selected experts (the process described in this study); and secondly create the basis for an open version, dedicated to all those interested in showing and sharing their typefaces, whether free, academic or professional scopes, that don't meet the criteria to take part of the curated version (the same criteria adopted above to select the sample for interviewing). This last version (still in study) is expected to bridge the gap between experts and initiates, contributing in a collaborative and pedagogical form, not only as an observatory of the type design community, but also hopefully serving as an incubator for the development of type design practices in Portugal.

Independently of the version, special focus was put on the potential users, exploring the many possible scenarios - the design students, professional designers, and in a broader sense all of those interested in the fields of type design and typography.

\subsection{Navigation structure, contents, links and workflow}

Several diagrams were put into test during the early stage of information architecture and database structure to better define categories, filters, and sorting methods, as well as users' roles in the system and workflow (Fig 3). 


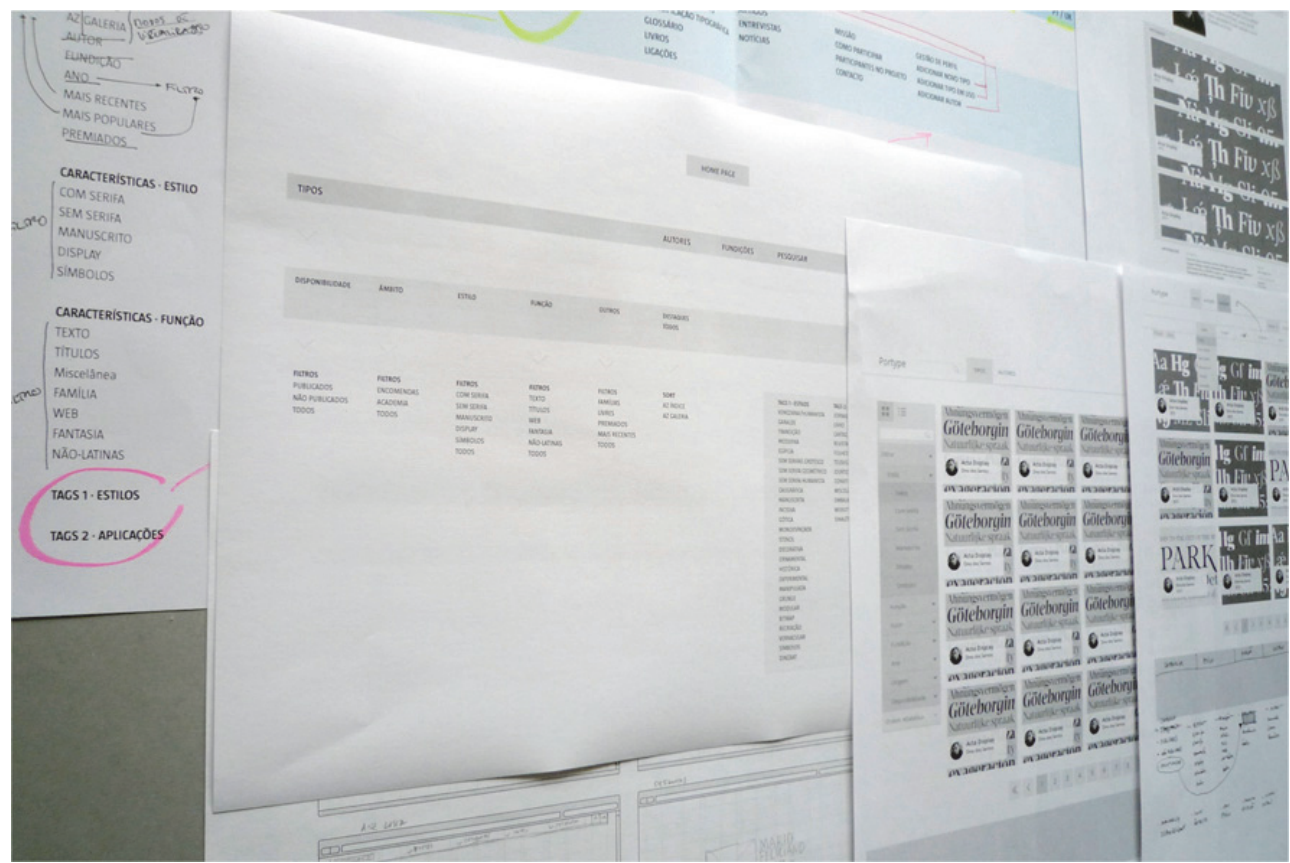

Fig. 3 The design process: Diagrams, sketches and first digital wireframes

In the first version, the prototype would allow users to view, search and identify typefaces based on a multitude of filtering and sorting methods, show detailed information of a typeface (name, author, year, availability, style, function, tags), through text descriptions, specimen images and examples of the type in use. Regarding the authors, the users could see an overview of the most relevant authors, access to the author specific information showing their biography, contact details, and their work organized according to the availability of their typefaces: published, custom, and unpublished typefaces. Users would also be allowed to contribute with more information, suggesting typefaces, authors or new examples of type in use.

Since the platform aspires to appeal to a wide audience, from design students to professional designers, and, in a broader sense, to all of those interested in the field of type design and typography, the amount and ways of navigating, sorting and filtering were striped down to the essential. We have tried to guide the user, even those who are new to the field, through a set of perceptible steps, according to the scenarios and user's role previously defined.

However, its features were not only based on the input received from the data previously obtained through the review of similar projects, neither from user's needs and desires, but also on the conventions and best practices within the field of design and interaction.

\subsection{Interaction design}

From the beginning, our approach to the interaction design pursued simplicity and easy to use, since it was mainly intended to be used specially by designers. We also knew the importance of ensuring that the interface presented to users from a non-technical background needs to be straightforward and easy to use. In interaction design, usability is a key concept when it comes to achieve these goals: effective to use (effectiveness), efficient to use (efficiency), safe to use (safety), have good utility (utility), easy to learn (learnability), easy to remember how to use (memorability) (Nielsen \& Tahir, 2002; Preece, Rogers \& Sharp, 2011). 
Hence it was necessary to ensure that the right amount of decisions, as well as functionality was provided to users.

From the information gathered previously a few items were considered a priority for the platform: the typefaces page, the typeface specific page, the authors page and the author specific page. In a first stage sketches were done in paper. The items and categories chosen were redefined in a second stage, where a series of alternative designs were experimented and tested to meet those requirements, but now with digital wireframes to test and evaluate again. In this phase we were not only concerned with the content, but also with technical issues since we wanted the platform to work well on several devices, meeting a responsive design. Most of the decisions were taken during this stage. In the third stage hi-fidelity wireframes were produced (Fig 4), to concentrate on design details and decisions, and put into test and evaluation.
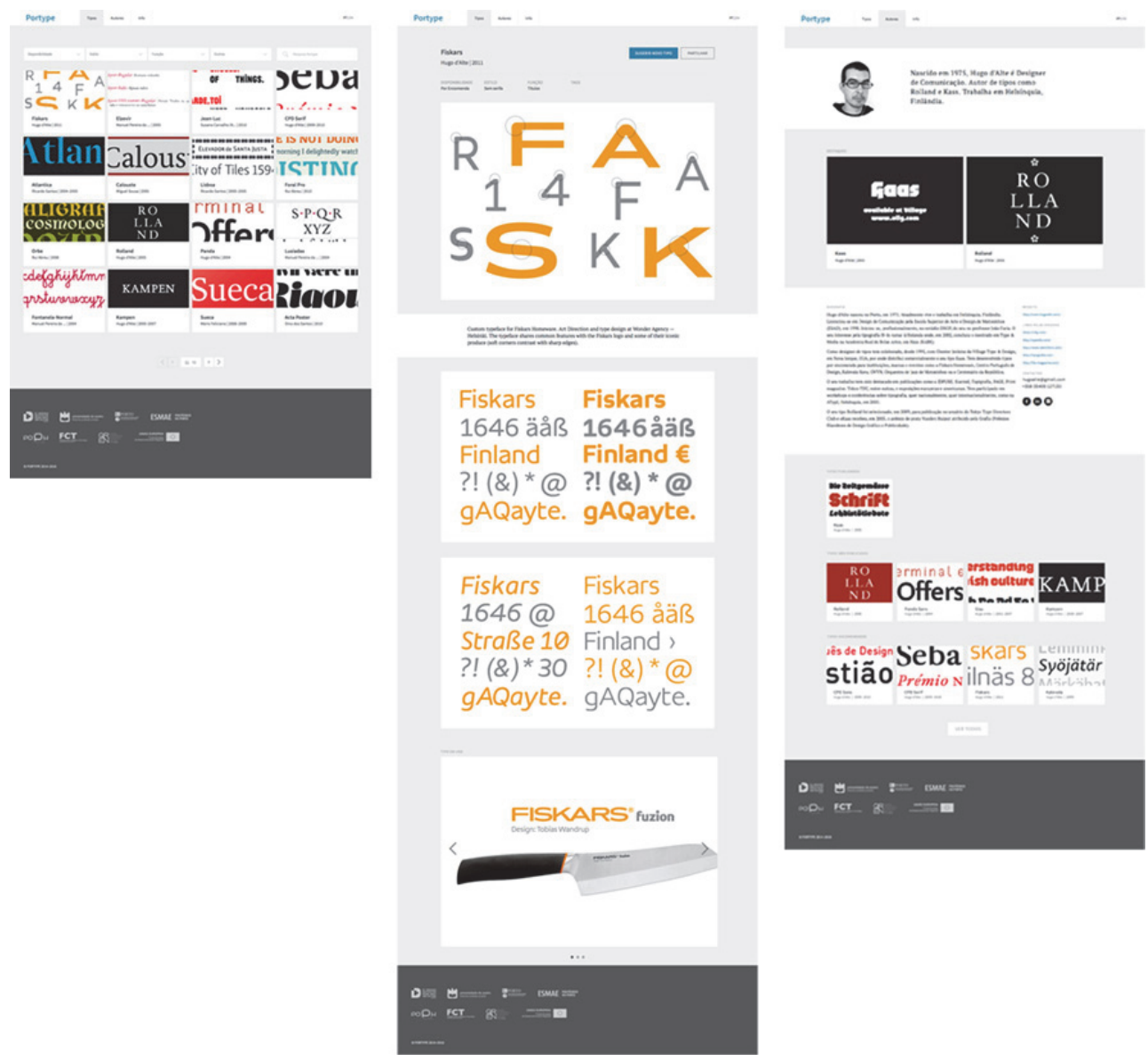

Fig. 4 Hi-fidelity digital wireframes: The typefaces page, the typeface specific page and the author specific page

\subsubsection{Brief description of the main functionalities}

For this version of the prototype the main functionalities tested were the homepage, the typefaces page, the typeface specific page, the suggestion page, the authors page and the author specific page. 

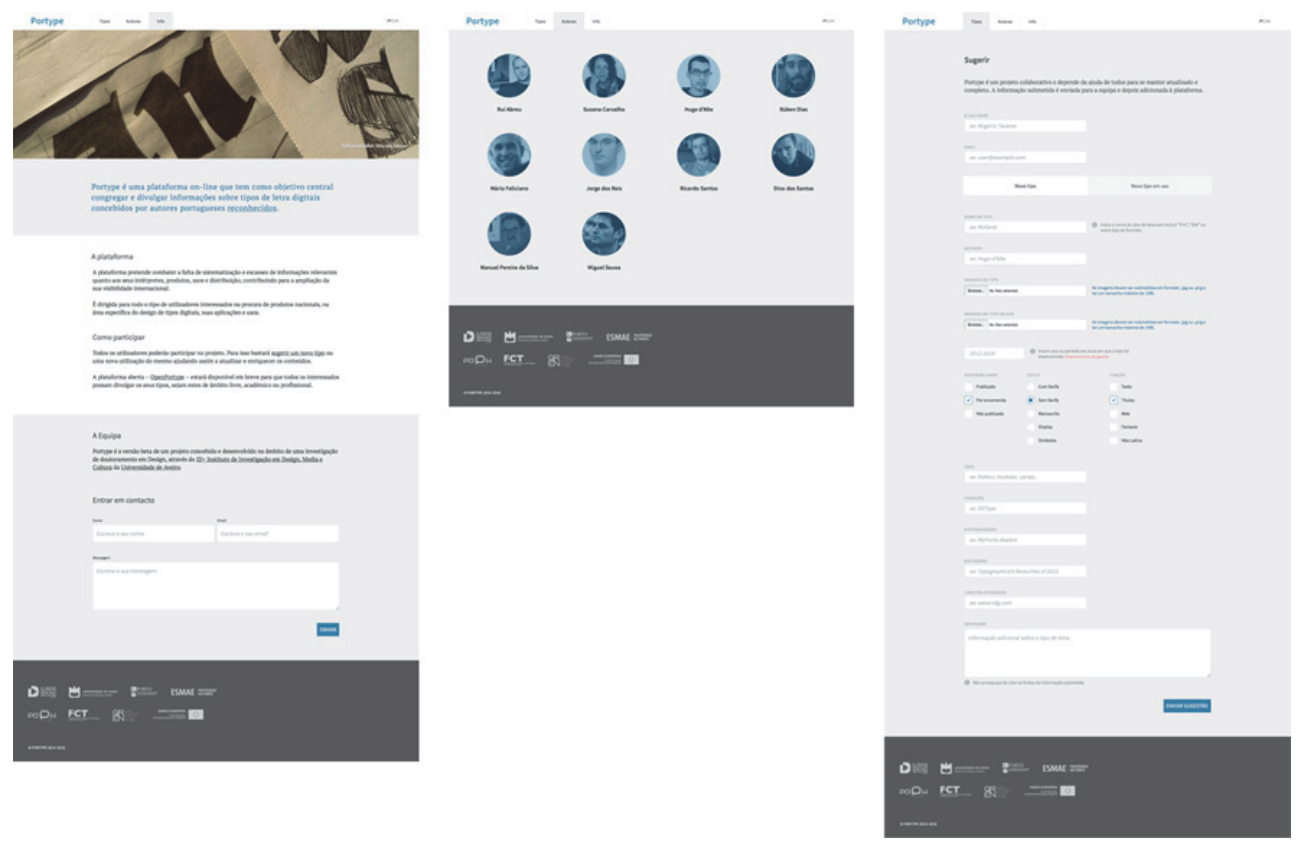

Fig. 5 Info, authors and suggest new typeface pages

The homepage shows the project general information (Fig 5) presenting at the top the main menu and the language selector. Then a slideshow is displayed followed by the project aims, a brief description on how users can collaborate, the team and ends with a brief contact form.

The typefaces page displays the curated grid based gallery of Portuguese digital typefaces (see Fig 4). Each typeface is represented with a specimen image, followed by the typeface name and year. At the top the system is divided into selection filters (availability; style; function; others), sorting methods (Order AZ; Most recent) and a search form, if user want to search a typeface based in other criteria, such as tags.

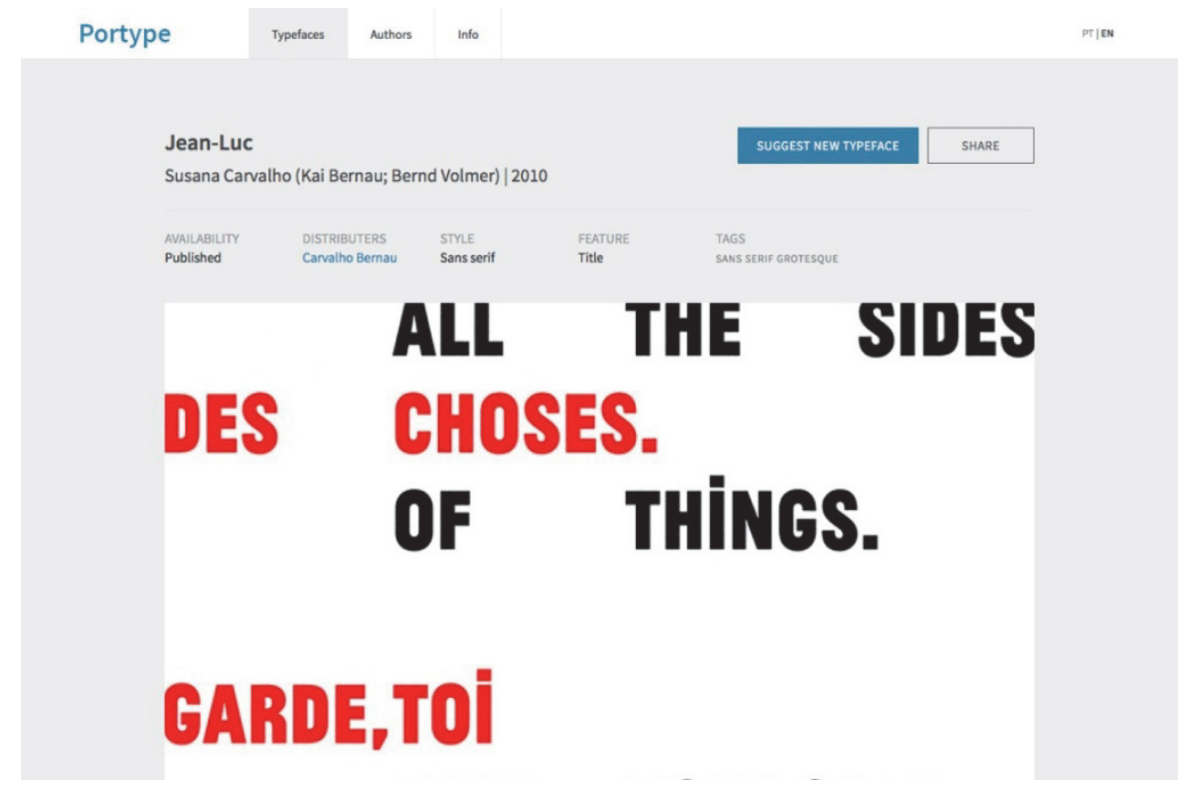

Fig. 6 Detail of Jean-Luc typeface specific page 
The typeface specific page retrieves the description topics from the database regarding the availability, distributers, style, feature, and tags (Fig 6). Several specimen images are displayed showcasing the typeface diversity and overall features followed by a scrolling gallery of the type in use. It ends with a suggested gallery of other typefaces from the same author. It's also possible to share the hole page or suggest a new typeface from the top links.

The suggestion page (see Fig 5) is divided into two options that the user needs to specify: suggest a new typeface or a new type in use. After specifying their choice, the form adapts to the information needed. In this curated version, all suggestions are recorded by the system and put on hold for further revision and approval.

The authors page, similar to the typefaces page, shows the selected type designers in a four column grid based layout (see Fig 5). Each author is displayed by a circular image that also represents the link interactive area.

The authors specific page holds complete information on each author (see Fig 4): highlighted and brief description of the author; two highlighted typefaces; biographical data; website; related links; contacts and social media. Then a gallery of typefaces organized by availability is displayed: published; custom; and unpublished typefaces.

\section{Implementation and evaluation}

A prototype was built from scratch to test the platform functionality, both through technical compliance tests, and user tests. Evaluating what has been built is very much in the center of interaction design (Preece, Rogers \& Sharp, 2011). It is important to develop a method for measuring user satisfaction with prototypes of future systems (Lewis, 1991).

In this phase we have conducted a questionnaire to measure user attitude and satisfaction with the first version of the prototype. The inquiry questionnaire was divided in three sections. The first section gathered information related with the characterization of the respondents (genre; age; professional activity; and the level of self awareness as a typography user). The second section recorded the agreement of users' opinions and attitudes according to three major dimensions: Overall Design, Interface and Contents. For that purpose, Osgood's semantic differential scale were used (Osgood, Suci \& Tannenbaum, 1957). A list of opposite adjectives gathered through contributions in the literature (BBC, 2002; Chin, Diehl \& Norman, 1988; Lewis, 1992; MacGregor \& Lou, 2005; Shaikh, 2009; UX for the masses, 2010) was developed in order to measure the platform connotative meaning in a seven-point scale. For the Overall Design dimension, these six opposed items were assessed: unpleasant/pleasant, traditional/contemporary, amateur/professional, unfriendly/friendly, confusing/clear, vulgar/elegant. In the Interface dimension: inadequate/adequate, inefficient/efficient, fragile/solid, complicated/simple, decorative/functional, difficult/easy. And in the Content dimension: common/rare, useless/useful, not recommended/recommended, irrelevant/relevant, insignificant/significant, general/specific. The third section measured the users' attitudes towards the prototype with four statements scored along a range of a five-level Likert scale (Strongly disagree; Disagree; Neither agree nor disagree; Agree; Strongly agree). The main focus was on ensuring that the project was useful and usable. We have adapted some of the contributions based in the literature from other surveys to meet our needs (Brooke, 1996; Davis, 1989; Lund, 2001). Thus, the range captures the intensity of the respondents feelings towards that aim.

The inquiry was applied to three groups of users (311 answers were considered valid): design students $(95,2 \%)$, teachers $(2,6 \%)$ and professionals $(2,2 \%)$. With the design students our focus was to evaluate the 
perceptions of beginners, usually with an incipient background on type design and typography in general, and with teachers and professionals the perceptions of experienced users.

Design students were obtained from the universe of Portuguese higher education institutions that offered a subject on Typography (5 universities and 3 polytechnic institutes). A total of eight institutions distributed all over Portugal, with both undergraduate $(74,2 \%)$ and master's courses $(25,8 \%)$, constituted the most significant part of our population sample $(95,2 \%)$.

Prior to the distribution and completion of the survey, a brief presentation of the researcher, the purpose and context of the research was conducted, as well as a demonstration of the functional prototype.

In the end, respondents could test themselves the prototype and filled out the anonymous survey. In the end some of the respondents shared their thoughts and suggestions, through a spontaneously conversation. All were noted down for future consideration.

Data was processed through statistical analyses, descriptive and inferential analysis, and were conducted to test for significance of the quantitative findings using IBM SPSS 22.0.

The sample revealed that the majority of the respondents were women $(63,3 \%)$, with an average of 21,67 years of age and a medium self perceived level of typography usage.

The output from the second section revealed that there is a good overall evaluation of the prototype.

Content was the dimension that met the highest classification $(M=6,39)$, followed by Interface $(M=6,33)$ and Overall Design $(\mathrm{M}=6,10)$.

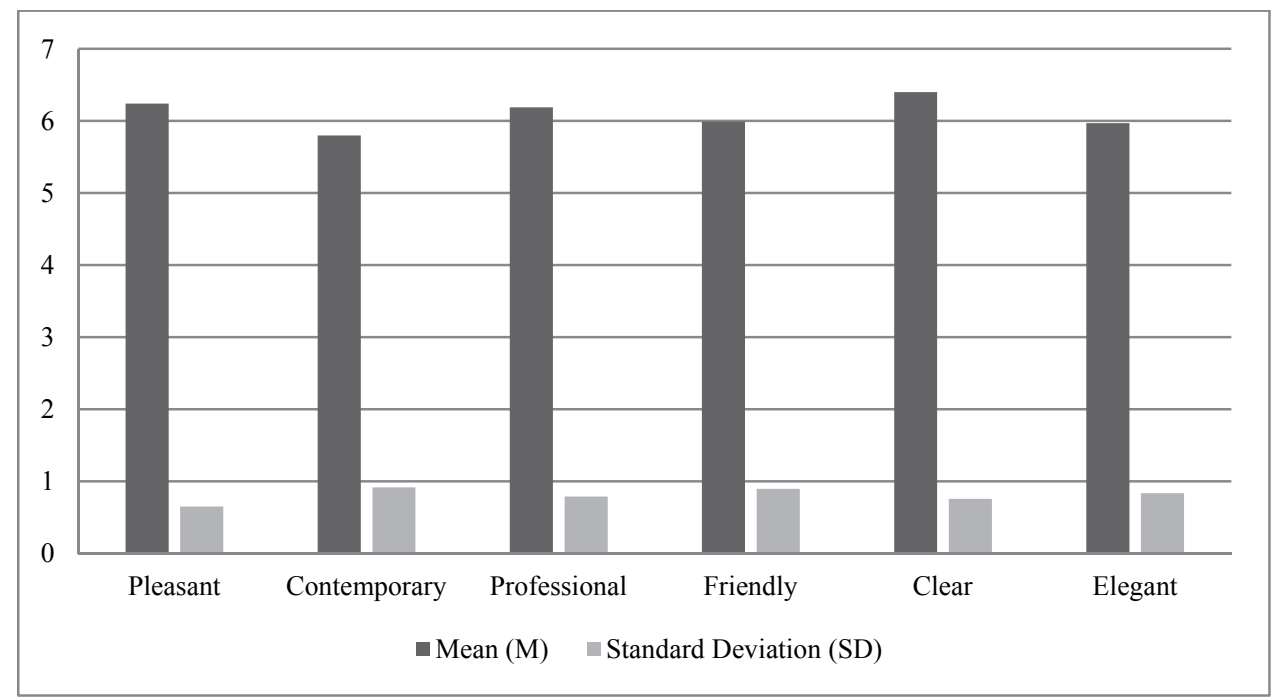

Chart 1 Overall Design $(M=6,10)$

In the Overall Design dimension, the item Clear is the one with the highest average $(\mathrm{M}=6,40)$ and the Contemporary item is the one with the lowest average of $(\mathrm{M}=5,80 ; \mathrm{SD}=0,917)$. Although that result represents a good average score, it denotes little agreement among respondents attested by the standard deviation which is also the highest in this items dimension. All other items are between 5,97 to 6,24. 


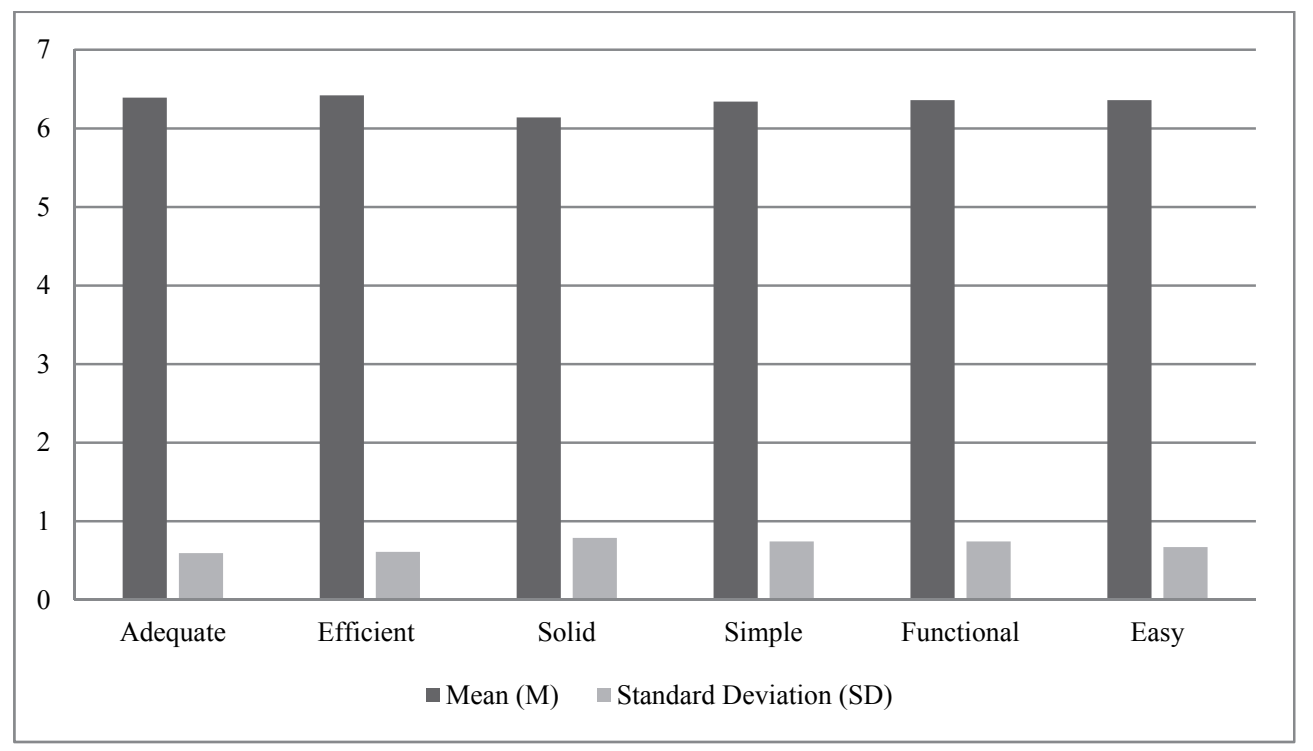

Chart 2 Interface $(M=6,33)$

In the Interface dimension, the item Efficient has the highest average $(M=6,42)$ and the Solid item is the one with the lowest average of $(\mathrm{M}=6,14 ; \mathrm{SD}=0,789)$.

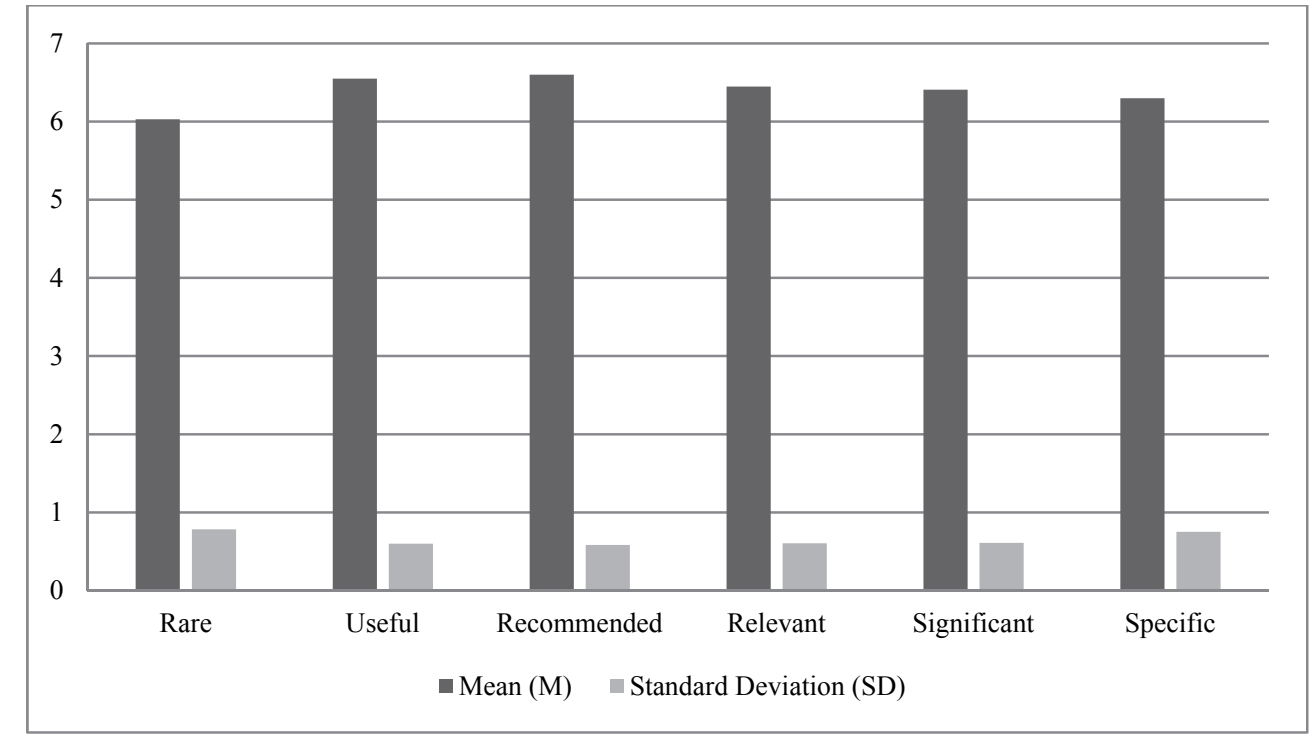

Chart 3 Contents $(M=6,39)$

In the Content dimension, the item Recommended has the highest average $(\mathrm{M}=6,60)$ and the Rare item has the lowest average $(M=6,03 ; \mathrm{SD}=0,784)$, but the standard deviation of this item shows the lack of consensus in the responses. All other items are positioned from 6,30 to 6,55.

In regards to the third section, respondents were especially in agreement with the fact that the project could bring more visibility and quality to national projects (Strongly agree: 59,6\%; Agree: 35,6\%). In general, the sample seems to agree that the project would take more authors to participate and motivate 
them to quality (Strongly agree: $42,9 \%$; Agree: $43,3 \%$ ), the regular usage of the project (Strongly agree: $36,2 \%$; Agree: $58,3 \%$ ), and with the recommendation of its use (Strongly agree: 19,9\%; Agree: 66,3\%).

With this data in hand we also wanted to test if there was significant differences in the evaluation of the Overall Design, Interface and Content according to genre, degree of study, and different professional activities. We have found that users from the master's courses evaluate the Overall Design and the Interface with lower classifications, but the inquiries with more than 35 years old have a better average evaluation.

Teachers revealed a statistically significant higher score in the evaluation of the platform interface. Users from 26 to 30 years old and with more than 35 years old recorded the highest scores in assessing the platform interface. Regarding the Content, respondents from the universities are the ones that better evaluate it .

These results are consistent with the hypothesis that the development of an online digital collaborative system would allow further development of knowledge of products, users and authors, as well as processes and uses. The questionnaire was a relevant tool to capture information regarding the system usefulness, information quality, interface quality.

\section{Conclusion}

This paper addressed the current system development of a platform for the disclosure of the Portuguese type design community, focusing on a group of selected type designers, from 1990 to 2010.

The systemic approach was revealed from the beginning of our research, where we had to find out the best possible ways to select the typefaces and their designers. The interviews conducted in the first stage of our study were crucial to deepen our understanding of their work and attitudes toward the development of the platform.

Review of the literature showed that there was a lack of uniformity among several authors which made it difficult to definitively choose one classification system as the most representative. This led us to systematically search for the most comprehensible terms, by studying different classification systems, comparing them with our research among the most representative type foundries and distributers, helped to gather information and refine our strategy towards the classification system used in the prototype, since we were aiming to appeal to a wide audience.

With that in mind, we have started to organize the information structure of the platform in order to fulfil the users' needs and expectations. For that purpose, after several tests during the initial phases of development (sketches; wireframes; hi-fi wireframes) the structure of the prototype was adjusted for a first test. Putting the users in the center of our approach was a very important step to inform us of their perceptions and needs. Evaluating systematically what was being built throughout the process was crucial (and still is). Searching the attitudes and behaviours of users is relevant especially for the development and improvement of the prototype.

The questionnaire developed to test the perceptions and attitudes of potential users made us aware of their needs and behaviour, highlighting how they perceived the prototype in the Overall Design, Interface and Content dimension, as well as their opinions regarding the usefulness of this project. The results revealed that users had a very good evaluation of the prototype rating all the dimensions with high values, highlighting the clarity of the design and that it is efficient and easy to use, which corroborated the 
hypotheses that the development of an online digital collaborative system would allow further development of knowledge between products, users and authors, as well as processes and uses.

One important finding of this study is that there was a good perception of the prototype aims, with the majority of users agreeing with the fact that the project could bring more visibility and quality to national typography taking more authors to participate and motivate them to quality. Most users agreed that they would regularly use the project and recommend its use to others.

Performing this test with the majority of respondents being students of design all over Portugal had an enormous impact in our research prospecting that the project will be well welcomed. Despite the positive feedback, it is still a prototype, with some improvements to make in the future to meet the users' expectations, mainly with issues related to both usability and contents. With the collaborative input from the users, we hope that the project contents become even more complete and up to date.

The project contributes to knowledge by presenting the methods and reasoning that support the design of digital typefaces while recording information from the past until the present. From the compilation of information on the subject, to the simplified classification mechanism; from the search, filtering and sorting capabilities, to the collaboration of users to increase the systems information. In short, involving the users as part of our research methodology turned out to be a valuable tool in the development of a platform for a wide possible spectrum of users. The current results on the platform development, with the improvements made through several user tests, evaluations and refinements undertaken in all phases of the project were crucial.

\section{References}

ANJOS, J. (1886). Manual do Typographo. Lisboa: David Corazzi Editor.

ANSELMO, A. (1981). Origens da Imprensa em Portugal. Lisboa: Imprensa Nacional.

ANSELMO, A. (1997). Estudos de História do Livro. Lisboa: Guimarães Editores.

BAUERMEISTER, B. (1987). A manual of comparative typography: The Panose System. New York: Van Nostrand Reinhold.

BBC (2002). The Glass Wall: the homepage redesign 2002. $<$ http://www.liamdelahunty.com/blog/media/theglasswall.pdf $>$ [Retrieved: 2016, may 1]

BRINGHURST, R. (2004 [1992]). The Elements of Typographic Style. $3^{\text {rd }}$ ed. Point Roberts, WA: Hartley \& Marks. (Originally published in1992)

BROOKE, J. (1996). "SUS: A 'Quick and Dirty' Usability Scale” in Jordan, P. W., Thomas, B., Weerdmeester, B. A., \& McClelland, A. L. (Eds.). Usability Evaluation in Industry. London: Taylor and Francis.

CAHALAN, A. (2007 [2004]). Type, Trends and Fashion: A Study of the Late Twentieth Century Proliferation of Typefaces. PhD thesis (2004). Curtin University of Technology, Perth, Western Australia. New York: Mark Batty Publisher.

CANHÃO, M. (1941). Os caracteres de Imprensa e a sua evolução histórica, artística e económica em Portugal. Lisboa, Porto e Coimbra: Grémio Nacional dos Industriais de Tipografia e Fotogravura.

CHACCUR, M., AMADO, P. (2010). “Os tipos de Além Mar” in Tupigrafia, 9, p. 62-69.

CHILDERS, T., GRISCTI, J., \& LEBEN, L. (2013). "25 Systems for Classifying Typography: A Study in Naming Frequency" in Parsons Journal for Information Mapping, vol. V, issue 1, winter 2013, p. 1-22.

CHIN, J.P., DIEHL, V.A., NORMAN, K.L. (1988). "Development of an Instrument Measuring User Satisfaction of the Human-Computer Interface" in ACM CHI'88 Proceedings, 1998 ACM, p. 213-218.

DAVIS, F. D. (1989). "Perceived Usefulness, Perceived Ease of Use, and User Acceptance of Information Technology" in MIS Quarterly, 13:3, p. 319-340. 
DIXON, C. (2001). A description framework for typeforms: an applied study. PhD thesis. London: Central Saint Martins / University of the Arts London.

DIXON, C. (2012). "The role of typeface categorization systems in the typographic education of the printer: a corrective legacy still with us today" in Design Frontiers: Territiories, Concepts, Technologies / Proceedings of the 8th Conference of the International Committee for Design History \& Design Studies - ICDHS 2012, São Paulo, Brazil: Blucher.

GOMES, R. (2010). O design brasileiro de tipos digitais: elementos que se articulam na formação de uma prática profissional. Master thesis. Rio de Janeiro: Escola Superior de Desenho Industrial, Universidade do Estado do Rio de Janeiro.

KING, E. (1999). New Faces: type design in the first decade of device independente digital typesseting (1987-1997). $\mathrm{PhD}$ thesis. London: Kingston University.

KING, E. (2001). "Digital Type Decade" in Eye, no. 40 vol. 10, summer 2001. $<$ http://www.eyemagazine.com/feature/article/digital-type-decade-full-text $>$ [Retrieved: 2016, may 1]

KINROSS, R. (1992). "The Digital Wave" in Eye, no. 7 vol. 2, summer 1992. $<$ http://www.eyemagazine.com/feature/article/the-digital-wave > [Retrieved: 2016, may 1]

LEONIDAS, G. (2013a). The next ten years. <http://leonidas.org/2013/03/12/thenexttenyears/> [Retrieved: 2016, may 1]

LEONIDAS, G. (2013b). Going Global: The Last Decade in Multi-Script Type Design. <http://typographica.org/ontypography/going-global-the-last-decade-in-multi-script-type-design/> [Retrieved: 2016, may 1]

LEWIS, J. (1991). "Psychometric Evaluation of an After-Scenario Questionnaire for Computer Usability Studies: The ASQ" in ACM SIGCHI Bulletin, 23 (1), p. 78-81.

LEWIS, J. (1992). "Psychometric Evaluation of the Post-Study System Usability Questionnaire: The PSSUQ" in Proceedings of the Human Factors Society 36th Annual Meeting, 1992, p. 1259-1263.

LUND, A.M. (2001) Measuring Usability with the USE Questionnaire. STC Usability SIG Newsletter, 8:2.

MACGREGOR, S., \& LOU, Y. (2005). "Web-Based Learning: How Task Scaffolding and Web Site Design Support Knowledge Acquisition" in Journal of Research on Technology in Education, vol. 37, n. 2, p. 161-175.

MIDDENDORP, J. \& TWOPOINTS.NET (2011). Type navigator: the independent froundries handbook. Berlin: Gestalten.

MUNDIE, D. (1995). A field guide to the faces. Pittsburgh, PA: Polymath Systems. $<$ http://www.dodomagnifico.com/686/Typography/Faces.html $>$ [Retrieved: 2016, may 1]

NIELSEN, J., \& TAHIR, M. (2002). Homepage usability: 50 Web sites deconstructed. Indianapolis, IN: New Riders.

OSGOOD, CHARLES .E.; G. SUCI AND P. TANNENBAUM (1957). The Measurement of Meaning. Urbana, IL: University of Illinois Press.

PACHECO, J. (1998). A Divina Arte Negra. O livro português. Séculos XV e XVI. Lisboa: Vega.

PACHECO, J. (2005). O Typographo na Contemporaneidade do Designer Gráfico. Phd thesis. Lisboa: Faculdade de Belas Artes da Universidade de Lisboa.

PACHECO, J. (2013). As artes gráficas e a imprensa em Portugal (séculos XV-XIX). A arte das artes. Lisboa: Instituto Superior Manuel Teixeira Gomes.

PATTON, M. Q. (2002). Qualitative research \& evaluation methods (3rd ed.). Thousand Oaks, CA: Sage.

PREECE, J., ROGERS, Y., \& SHARP, H. (2011). Interaction Design: Beyond Human-Computer Interaction. New York: John Wiley \& Sons Ltd.

PROVIDÊNCIA, F. (2003). "Algo más que una hélice” in Calvera, A. (ed.) Arte ¿? Diseño. Barcelona: Gustavo Gili, p. 195-213.

QUELHAS, V., BRANCO, V., \& HEITLINGER, P. (2011). "The languages of Typeface Design in Portugal" in Strategic Design Research Journal, 4(2) p. 84-92 May-August. Unisinos - doi: 10.4013/sdrj.2011.42.07.

SHAIKH, A. (2007). Psychology of onscreen type: investigations regarding typeface personality, appropriateness, and impact on document perception. PhD Thesis. Wichita State University. 
SHAIKH, A. DAWN (2009). "Know Your Typefaces! Semantic Differential Presentation of 40 Onscreen Typefaces" in Usability News, October 2009, vol. 11, issue 2. < http://usabilitynews.org/know-your-typefaces-semanticdifferential-presentation-of-40-onscreen-typefaces/ > [Retrieved: 2016, may 1]

BS 2961 (1967). Specifications for type face nomenclature \& classification BS 2961:1967. Londres: British Standards Institution.

SPIEKERMANN, E. \& GINGER, E. (1993). Stop Stealing Sheep \& Find Out How Type Works. Mountain View, California: Adobe Press.

THIBAUDEAU, F. (1924). "Classification des caractères d'imprimerie" in Thibaudeau, F., Manuel Français de Typographie Moderne. Paris: Bureau de l'édition, p. 37-109. 